\title{
DIGITALISATION OF FINANCIAL SERVICES AND FINANCIAL LITERACY OF YOUNG GENERATIONS - TRENDS, CHALLENGES AND SOLUTIONS FROM BULGARIAN PRACTICE
}

\author{
Mariyana Bozhinova ${ }^{1}$, Alexander Ganchev ${ }^{2 *}$ \\ ${ }^{1}$ Prof., Dimitar A. Tsenov Academy of Economics, BULGARIA, m.bozhinova@uni-svishtov.bg \\ ${ }^{2}$ Assoc. Prof., Dimitar A. Tsenov Academy of Economics, BULGARIA, a.ganchev@uni-svishtov.bg \\ ${ }^{*}$ Corresponding Author
}

\begin{abstract}
The report examines the relationship between the digitalisation of economy and financial services and the risks it poses in terms of financial literacy levels of younger generations. It outlines trends in the digitalisation of financial processes, investment operations and trade and highlights how they lead to new risks and challenges as well as how they can be minimized by increasing financial literacy, especially for children and students. The paper focuses on the Bulgarian practice in raising financial literacy levels of the Generation Z and its positive examples. The study shows that the digitalisation of trade and financial services in recent years has made banking operations, payment services, investment instruments and trade more accessible. This increases the risk of young people suffering economic losses as a result of manipulations in social media, use of financial services that are not protected by regulators, investing in companies or assets with no fundamental value or even as a result of financial fraud. A high level of financial and digital literacy plays a key role in reducing the above-mentioned threats. Data show that in Bulgaria the levels of financial and digital literacy are low and they are below the average levels for the world and in OECD countries. This requires a set of measures to be taken by the government, the business and the educational institutions. Until now, the major role in raising the financial literacy of young people in Bulgaria has had financial institutions and banks. Since 2021, the central government has been seriously involved in these issues. There are also positive examples of the participation of Bulgarian universities and non-governmental organizations in the initiatives to raise the financial literacy of the younger generations in the country.
\end{abstract}

Keywords: digital economy, financial literacy, fintech companies, financial risks.

\section{INTRODUCTION}

The modern world is characterized by dynamism and constant change towards modernization and automation in all spheres of social life. The penetration of Internet services, cloud technologies, artificial intelligence and smart devices in recent years has led to a significant transformation of all social and economic processes in the field of trade and financial services. Their digitalisation has been particularly noticeable over the last few years and the process has intensified tremendously under the conditions of COVID-19.

The digitalisation of trade and financial services creates suitable conditions for their decentralization and 
liberalization. With the help of the Internet, mobile phones and mobile applications, these services are now available at any time and any place in the world. Competition in economy on a global scale is also intensifying as in the digital age local retailers and financial product suppliers have already been operating under pressure from retailers and financial institutions around the world. This leads to increasingly favourable and acceptable conditions for the consumers. Increasing access to economic and financial processes inevitably attracts more and more members of the generation born around the eve of the new millennium, i.e. the Generation Z (Gen Z). Its members are characterized by spending a lot of time on the Internet, a desire for change and rebellion against the norms as well as criticism of the authorities.

However, digitalisation of the economy and finance leads to the fact that young people, including young people in Bulgaria, have to make financial, investment and economic decisions more often. It is necessary to know the trends in the digitalisation of economic and financial processes, the extent to which young people deal with information technology and information and the possible risks involved in order for the society to provide adequate solutions to the growing involvement of young people in economic and financial processes without exposing them to risks and with the aim of improving their quality of life. In this regard, the subject of research in the present study is the relationship between the digitalisation of the economy and finance, on the one hand, and the financial literacy of the younger generations, on the other. The aim of the study is to outline the main trends, challenges and risks related to the digitalisation of economic processes and financial services and to consider how they could be avoided by improving the financial literacy of Generation Z and especially young people in Bulgaria. Based on this, the rest of the report is structured into five main parts. Part 2 describes the trends in digitalisation of economy and finance. Part 3 contains a systematic analysis of the risks arising from digitalisation of the economy and finance. Part 4 presents the challenges related to eliminating the threats of digitalisation of economic processes for the younger generations in Bulgaria. Part 5 shows the possible solutions to the problems related to low financial literacy in Bulgaria. The last part of the report summarizes the main conclusions and formulates directions for further research on the topic of the study.

\section{TRENDS IN THE DIGITALISATION OF GLOBAL ECONOMY}

It is no secret that the process of digitalisation in the world economy has intensified enormously in recent years. It started at the beginning of the 21st century, but it has only taken shape in recent years, with the pandemic of the new coronavirus giving a very strong boost to businesses using digital and online platforms. In this context, main trends in the digitalisation of the economy and the financial system in recent years are related to:

First. Increasing Internet commerce and digitalisation of trade processes;

Second. Digitalisation of banking operations and payments;

Third. Digitization and democratization of the investment process;

Fourth. Digitization of economic relations with the state;

Fifth. Extensive use of blockchain technology in the economy and increasing the popularity of cryptocurrencies.

The first and most evident trend and perhaps the oldest one in the digitalisation of the economy, is the growing role of internet commerce, which is carried out at national and international level. It is mainly done through websites and mobile trading platforms. The most influential global ones are undoubtedly Amazon and AliExpress/Alibaba, and the evidence of their growing influence in the global economy is the very strong growth of their financial results over the last 4 years (UNCTAD, 2021, p. 25). However, their global, regional and national alternatives are significantly smaller. Increasing digitalisation of trade flows leads, in turn, to the need for next level of economic digitalisation. This is the digitalisation of payment services and banking operations.

Today, the growth in the use of mobile platforms for payment services and banking operations is becoming more and more evident. There are hardly any banks in the developed countries, which have not transferred most of their operations online through their internet banking platforms. Moreover, due to their low interest income, commercial banks increasingly stimulate their customers to use online banking services. However, many of the platforms for digital banking operations are products of various fintech companies such as PayPal or the Bulgarian Paysera. These platforms develop a wide range of very cost-effective payment services. Some other digital financial platforms, such as Revolut, provide banking services. This makes banking and payment services much more accessible, and their use - popular, much easier and much faster. Digitalisation of financial services allows the development of banking or payment products even for children 
and young people. Such products are offered by the fintech platform Revolut through its children's accounts, and leading commercial banks in Bulgaria offer debit cards for children.

The investment process is also undergoing a major change and adjustment to the realities of the digital age. Along with the traditional ways of investing through licensed investment intermediaries and their trading platforms, more and more fintech platforms such as eToro, Revolut, Plus500, Robinhood, etc. are emerging, providing an opportunity to invest in global financial markets. Moreover, these platforms allow investments in different markets at the same time. In order to facilitate their work, the above-mentioned fintech platforms have mobile applications. What makes them very attractive to consumers is the opportunity they offer for investing small amounts of money as well as the fact that there are no transaction costs in most of them. That is the reason why fintech platforms offering investment opportunities are gaining popularity and a wider range of customers of all ages, including young people, students and university students.

Digitalisation of the economic relations with the state is the next aspect of the penetration of information technology in the economy. Currently, this process in Bulgaria is slower. Nevertheless, the economic relations of the citizens with the state and the state bodies regarding the repayment of tax liabilities or payment of state fees have already been digitized and transferred to the Internet. This creates convenience, but it also raises the need to know the philosophy of taxation or technology of state revenue collection.

The blockchain technology and one of its applications in the form of cryptocurrencies are a particularly clear indicator of the digitalisation of financial and economic processes over the past decade. Currently, there are 8,303 cryptocurrencies (Coinmarketcap.com, 2021) with a total market capitalization of approximately $\$ 2.7$ trillion (Finance.yahoo.com, 2021). Although the financial community is not unanimous about the nature of cryptocurrencies and their applicability, they are growing in popularity as an investment or means of payment. This is especially true for young people. However, this requires adults and especially young people to have knowledge of the nature of the investment process, as well as the nature and functions of money as an economic phenomenon. This is of particular importance in view of the gaining popularity investments in Non-fungible Tokens, known by their English acronym NFT (Forbes.com, 2021).

\section{THE RISKS OF THE DIGITAL FINANCE WORLD}

The processes of digitalisation, liberalization and democratization of financial services and the economic processes in the world are generally accompanied by a number of risks. Many of them are completely new and different from the traditional risks associated with the traditional investment or use of financial and insurance products. The risks stem directly from the process of digitalisation and the widespread use of social networks, and they are superimposed on the pre-existing financial and economic risks, inherent in any financial or investment decision. This makes modern financial and investment environment much more complex compared to the traditional one, which means that the overall risk to personal finances in the digital age is growing significantly and hence the likelihood that young people will realize losses and deteriorate their economic status. Some of the new risks resulting from the digitalisation and decentralization of trade, financial and investment services may include opportunities for committing fraud, phishing attacks, investments in assets with no significant fundamental value, the provision of financial services by insufficiently or poorly regulated technology companies and the possibilities for manipulating economic decisions through social networks.

Financial fraud and theft have always been part of economic life. However, the digitalisation of financial processes can activate ill-wishers to add to their material wealth at the expense of other people who lack good digital financial literacy. Skilful phishing attacks as well as installation of unverified software on mobile devices can lead to draining funds from personal accounts, personal data theft or even assumption of financial obligations. In turn, the use of investment platforms that are not subject to regulation or are poorly regulated can lead to a loss of all invested funds. This was the case with the Turkish crypto exchange Thodex, whose founder went missing taking \$2 billion of investors' funds with him in April 2021(DW.com, 2021).

The inherent risks in technology companies as business entities can also be defined as very serious and significant in today's economic environment. A large number of the new and digitalised financial services are provided by technology companies rather than traditional financial companies. It is for this reason that using payment services, storing cash or investing through different platforms such as PayPal, Alipay, Google Pay or Revolut sometimes does not mean providing the same consumer protection as banks, which, in the European Union, are required to comply with the strict regulations of the Payment Services Directive (The European Parliament and of the Council, 2015).

Manipulations over social media should not be underestimated, either. The opportunity of a great number of 
people, including young people, with poor financial culture to use financial services or invest small amounts of money without transaction costs through platforms such as eToro, Revolut, and in the United States through the Robinhood platform, combined with the use of social networks can create conditions for manipulations. These manipulations of investment behaviour can ultimately lead to big profits, but they can also lead to big losses for ordinary investors. Such was the case with the volatility of GameStop's shares in January 2021. Another factor that increases the analysed risk is following celebrities from economic and financial life on social media, such as Elon Musk. Thus, investment in highly speculative cryptocurrencies or financial assets can be made on the basis of publications of various celebrities about their investment intentions. This poses a significant risk because there is virtually no guarantee that the posts of various influencers on social networks focusing on investment do not constitute deliberate manipulation.

An important risk arising from the digitalisation of economy and finance is the impact of online advertising. The widespread use of smartphones and social networks makes it possible to target advertising for the use of financially and investment-oriented applications. In this way people, young people in particular, with low financial literacy can be tricked into making financial or investment decisions without being aware in detail of their nature, variety or associated risks of losses.

\section{THE LEVEL OF FINANCIAL LITERACY OF YOUTH IN BULGARIA}

In order to minimize the negative consequences of the above-mentioned risks caused by the digitalisation of the economic and financial world, greater level of financial and digital literacy is needed among the elderly population and Generation Z in particular. Therefore, it is not a coincidence that both types of literacy have been the subject of increasing research worldwide in recent years. Bulgaria is no exception to these trends, either. One of the most thorough studies on the level of financial literacy in Bulgaria at present is the one conducted by the Organization for Economic Cooperation and Development (OECD) in 2020. It is titled "Financial Literacy of Adults in South East Europe" and its results show that (OECD, 2020a):

First. Financial literacy among the population of Bulgaria is around the average for Southeast Europe.

Second. Financial literacy among young people is by $13.11 \%$ lower in comparison to the $30-59$ age group and by $7.02 \%$ lower, compared to people over 60 , which is very worrying.

Financial literacy in Bulgaria also lags far behind the world average. Another OECD survey from 2020 (OECD, 2020b, p. 17) shows that:

First. The indicators of the level of general financial literacy in Bulgaria are about $17.72 \%$ lower than the countries that are world leaders in the field.

Second. Compared to the world average, Bulgaria lags behind in the range of $3.31 \%$.

Third. Regarding the OECD member states included in the study, the level of financial literacy in Bulgaria is lower by $5.65 \%$.

Findings concerning the relatively low average level of financial literacy among young people and students were confirmed by the results of the financial literacy module within the PISA 2018 survey, announced in early 2020. The calculations made on the basis of the announced results (Vasileva, 2020) give grounds to draw the following conclusions:

First. Bulgarian students' level of financial literacy is average by $14.46 \%$ lower than the average for OECD members and over $21 \%$ lower than the leader Estonia.

Second. In vocational and non-specialized schools in the field of economics in Bulgaria, the results are even lower, respectively by $21.39 \%$ and $21.19 \%$ compared to the OECD average.

Third. The level of financial literacy of Bulgarian girls exceeds that of the boys by 19 points, but remains below the general average levels examined in the survey.

In this context, the levels of digital literacy among Bulgarian students and young people are also worrying. Eurostat data (Eurostat, 2020), published in July 2020, show that in terms of digital skills Bulgarian youth between the ages of 16 and 24 rank penultimate among EU countries. According to the survey, their level of digital literacy is $58 \%$ in comparison to the EU average of $80 \%$ (Eurostat, 2020).

The presented data from authoritative studies show that young people and university students in Bulgaria are highly exposed to dangers and risks arising from the digitalisation of the financial system and economy. Moreover, the lack of knowledge concerning the nature of economic processes, the financial system and the investment process is a significant obstacle to the entrepreneurial skills development of the members of 
Generation $\mathrm{Z}$ in Bulgaria in the conditions of an increasingly digital economy.

\section{BULGARIAN EXPERIENCE IN INCREASING FINANCIAL LITERACY OF GEN Z}

The unsatisfactory levels of digital and financial literacy among students and young people in Bulgaria require fast, targeted and complex measures and actions, adequate to the realities. Moreover, they must be implemented on multiple levels to be as effective as possible. Government policy should definitely be the first step in any strategy for improving the financial literacy. Until 2021, such a strategy was virtually non-existent in Bulgaria but the first steps in the process of government's growing engagement with the issue have already been taken. Thus, the Bulgarian government has recently adopted the National Strategy for Financial Literacy of the Republic of Bulgaria for the period 2021-2025. (Council of Ministers of the Republic of Bulgaria, 2021). The document mainly addresses the levels of financial literacy among young people and sets out the priority areas for impact. Nevertheless, the Bulgarian government's efforts to address the problem of low financial literacy can be described as timely and commendable. As far as digital literacy is concerned, what is set as an operational goal of the National Youth Strategy for the period 2021-2030, approved by the Council of Ministers of the Republic of Bulgaria (National Youth Strategy 2021-2030, 2021, pp. 27-28) is improving young people's skills for working with modern digital tools. However, the review of the document shows that the development of digital skills among young people in our country is not sufficiently addressed in that strategy. This means that, in terms of digital literacy, government policies are still lagging behind society's needs. This, in turn, creates a vacuum that is currently being filled by NGOs, business representatives and the financial sector, which is also a major provider of digital financial services for young people. Successful examples in this direction are initiatives such as Raiffeisenbank's Bank Hour (Raiffeisenbank Bulgaria, 2020) or DSK Bank's Financial Literacy Program (DSK Bank, 2019) and Expat Capital's Financial Literacy Education Project. (Expat.bg, 2021). Efforts to improve the financial literacy of children and students, made by financial portals such as MoitePari.bg (MoitePari.bg, 2021) and economic media such as Bloomberg TV Bulgaria (Bloombergtv.bg, 2021), are also commendable.

There are positive trends related to the participation of economic universities in the process of increasing financial and digital literacy of students and youth in Bulgaria. A good example of such participation is the goal and mission of the project "Increasing the financial literacy and economic culture of students from 5th to 10th grade in Bulgarian schools", developed by the Ministry of Education and Science and the Union of Bulgarian Teachers whose contractor as a training institution is Dimitar A. Tsenov Academy of Economics Svishtov. The project had its first successful edition, in which students and teachers from 94 high schools in Bulgaria were trained in subjects such as General theory of economics, Money and Credit, Insurance, Taxes and other public receivables, and Entrepreneurship. By the end of 2021, the project already has a second edition, which will cover the districts of Sofia-city, Sofia-district, Pernik, Kyustendil and Blagoevgrad. Therefore, such initiatives for improving the financial literacy of young people can be considered successful. Moreover, they should be encouraged because they are an example of successful cooperation between government, NGOs and universities, and this is a guarantee for achieving the ultimate goal - increasing the financial literacy of Generation Z.

\section{CONCLUSION}

The study examines the main aspects of digitalisation of global economic and financial processes and the risks it poses. The main conclusion that can be drawn from the data presented in the survey is that the trends in the development of the world economy and the digitalisation of financial services pose serious risks to younger generations. Risks are related to the likelihood that they will suffer economic losses due to financial fraud over the internet, inherent risks in technology companies, manipulation of investment decisions via social networks and the impact of online advertising. The other conclusions from the research can be formulated as follows:

First. The level of financial literacy of young people in Bulgaria is low, below the average levels of OECD countries and below the world average. The situation is the same with regard to their digital competencies. This means that there are serious risks for the members of Generation Z in Bulgaria to make wrong economic and financial decisions that can lead to financial losses.

Second. Addressing the risks and challenges of low financial literacy requires a set of measures that include public policies, educational policies implemented by financial institutions and, above all, strengthening the role of universities in the process.

Third. The project "Increasing the financial literacy and economic culture of students from 5th to 10th grade in Bulgarian schools", implemented by the Ministry of Education and Science in the Republic of Bulgaria, the 
Union of Bulgarian Teachers at the Confederation of Independent Trade Unions in Bulgaria and Dimitar A. Tsenov Academy of Economics - Svishtov is an example of good practice in the process of increasing the financial literacy of children and students in Bulgaria.

Certainly, this paper does not fully address the problems of financial literacy of children and students in Bulgaria and the risks associated with it. In order to clarify the problems and adequately address them, a detailed analysis of government measures in this area and the formulation of proposals for their improvement and dynamization are needed. This is where attention should be focused for further work on the research topic.

\section{REFERENCE LIST}

Bloombergtv.bg. (10 11 2021). Smart chas. Retrieved from Balguarskata obrazovatelna igra, koyato shte napravi detsata finansovo gramotni: https://www.bloombergtv.bg/a/44-smart-chas/98845-balgarskataobrazovatelna-igra-koyato-shte-napravi-detsata-finansovo-gramotni

Coinmarketcap.com. (16 12 2021). Coinmarketcap.com. Retrieved from coinmarketcap.com: https://coinmarketcap.com/

Council of Ministers of the Republic of Bulgaria. (12 02 2021). Natsionalna strategiya za finansova gramotnost na Republika Balgariya (2021-2025). Retrieved from Ministerski savet, Portal za obshtestveni konsultatsii: https://www.strategy.bg/FileHandler.ashx?fileld=25615

DSK Bank. (11 07 2019). Banka DSK startira programa za povishavane na finansovata gramotnost sred uchenitsite i tehnite roditeli. Retrieved from dskbank.bg: https://dskbank.bg/\%D0\%BC\%D0\%B5\% D0\%B4\%D0\%B8\%D1\%8F-\%D1\%86\%D0\%B5\%D0\%BD\%D1\%82\% D1\%8A\%D1\%80/\%D0\%BA\%D0\%BE\%D1\%80\%D0\%BF\%D0\%BE\%D1\%80\%D0\%B0\%D1\%82\%D0\% B8\%D0\%B2\%D0\%BD\%D0\%B0-\%D1\%81\%D0\%BE\%D1\%86\%D0\%B8\%D0\%B0\%D0\%BB\% D0\%BD\%D0\%B0-\%D0\%BE\%D1\%82\% D0\%B3\%D0\%BE\% D0\%B2\%D0\%BE\%D1\%80\%D0\%

DW.com. (04 22 2021). Turkish cryptocurrency platform founder vanishes, fraud suspected. Retrieved from www.dw.com: https://www.dw.com/en/turkish-cryptocurrency-platform-founder-vanishes-fraudsuspected/a-57302955

Eurostat. (2020). Do young people in the EU have digital skills? Retrieved from https://ec.europa.eu/: https://ec.europa.eu/eurostat/web/products-eurostat-news/-/edn-20200715-1

Expat.bg. (10 11 2021). Zashto e vazhna finansovata gramotnost i kak da govorim za pari, investitsii i lichni finansi s detsata si? Retrieved from https://www.expat.bg/bg/news/natalia-todorova-zashto-e-vazhnafinansovata-gramotnost-i-kak-da-govorim-za-pari-investitsii-i-lichni-finansi-s-detsata-si

Finance.yahoo.com. (23 11 2021). Total Crypto Market Cap Drops Below $\$ 2.7$ Trillion as Correction Continues. Retrieved from finance.yahoo.com/: https://finance.yahoo.com/news/total-crypto-marketcap-drops-084646257.html

Forbes.com. (14 05 2021). What You Need tso Know About Non-Fungible Tokens (NFTs). Retrieved from: Forbes.com: https://www.forbes.com/advisor/investing/nft-non-fungible-token/

MoitePari.bg. (09 09 2021). Finansova gramotnost za detsa - vazhna e! Retrieved from MoitePari.bg: https://www.moitepari.bg/spravochnik/art/advices/finansova_gramotnost 433872fc-d101-4586-8c38$748 \mathrm{bc} 713 \mathrm{df} 7 \mathrm{e} /$

OECD. (2020a). Financial Literacy of Adults in South East Europe. Retrieved from: https://www.oecd.org/financial/education/Financial-Literacy-of-Adults-in-South-East-Europe.pdf

OECD. (2020b). OECD/INFE 2020 International Survey of Adult Financial Literacy. Retrieved from www.oecd.org: https://www.oecd.org/financial/education/oecd-infe-2020-international-survey-of-adultfinancial-literacy.pdf

Raiffeisenbank Bulgaria. (08 12 2020). "Chasat na bankata" ogramotyava finansovo uchenitsi v onlain sreda. Retrieved from www.rbb.bg: https://www.rbb.bg/bg/za-bankata/novini-analizi/novini/2020/chast-nabankata-ogramotyava-finansovo-uchenici-v-onlajn-sreda/ 
The European Parliament and of the Council. (25 11 2015). Directive (EU) 2015/2366 of The European Parliament and of the Council of 25 November 2015 on payment services in the internal market. Retrieved from: eur-lex.europa.eu: https://eur-lex.europa.eu/legalcontent/EN/TXT/HTML/?uri=CELEX:32015L2366\&from=BG

UNCTAD. (2021). Digital Economy Report 021. Retrieved from https://unctad.org/: https://unctad.org/system/files/official-document/ der2021_en.pdf

Vasileva, N. (2020). Balgarskite petnadesetgodishni uchenitsi i parite. Rezultati ot uchastieto na Balgariya $v$ modul finansova gramotnost v PISA 2018. Retrieved from Tsentar za otsenyavane v preduchilishtnoto i uchilishtnoto obrazovanie: http://copuo.bg/upload/docs/2020-05/FinLit_PISA2018_BGR.pdf

National Youth Strategy for the period 2021-2030. (14 1 2021). Ministerski savet, Portal za obshtestveni konsultatsii. Retrieved from https://www.strategy.bg/FileHandler.ashx?fileld=23729 